\title{
Review of Major Theories of Skin Aging
}

\author{
Alfredo Gragnani ${ }^{*}$, Sarita Mac Cornick ${ }^{2}$, Verônica Chominski², \\ Samuel Marcos Ribeiro de Noronha ${ }^{2}$, Silvana Aparecida Alves Corrêa de Noronha ${ }^{2}$, \\ Lydia Masako Ferreira ${ }^{2}$ \\ ${ }^{1}$ Division of Plastic Surgery, Department of Surgery, Federal University of Sao Paulo, Paulista School of \\ Medicine (UNIFESP-EPM), Sao Paulo, Brazil \\ ${ }^{2}$ Division of Plastic Surgery, Department of Surgery, UNIFESP-EPM, Sao Paulo, Brazil \\ Email: ${ }^{*}$ alfredogf@ig.com.br
}

Received 4 June 2014; revised 9 July 2014; accepted 19 August 2014

Copyright (C) 2014 by authors and Scientific Research Publishing Inc.

This work is licensed under the Creative Commons Attribution International License (CC BY).

http://creativecommons.org/licenses/by/4.0/

(c) (i) Open Access

\section{Abstract}

Here we aim to describe each factor that leads to skin aging and describe their mechanisms. A PubMed database searches (from January 2004 to March 2014) using aging and skin as searched terms. There are substantial evidences showing that aging is associated with damage from free radicals represented by various reactive oxygen species (ROS). Mitochondria are producers and also targets of oxidative stress. The cycle of mitochondrial dysfunction can trigger the aging process. In the cellular senescence and telomeres theory, the diploid cells exhibit a limited proliferation potential. After a finite number of divisions, they enter a state of senescence with a stop replication in cell proliferation. It is suggested that aging is associated mainly with hyper-regulation of apoptosis. Obesity presumably accelerates the process of aging, which is aggravated by smoking. And the influence of the environment, called solar UV irradiation is of considerable importance to skin aging. There are several mechanisms that trigger the natural aging process and contribute to age-related changes, including oxidative stress theory of free radicals, the mitochondrial dysfunction, telomere shortening, UV radiation and other mechanisms that taken together or alone may or not accelerate the change in skin.

\section{Keywords}

Aging, Genetics, Reactive Oxygen Species, Telomerase, Cell Senescence

\section{Introduction}

The skin acts as a protective barrier between the internal organs and the body and the environment. It is divided

"Corresponding author.

How to cite this paper: Gragnani, A., Cornick, S.M., Chominski, V., de Noronha, S.M.R., de Noronha, S.A.A.C. and Ferreira, L.M. (2014) Review of Major Theories of Skin Aging. Advances in Aging Research, 3, 265-284.

http://dx.doi.org/10.4236/aar.2014.34036 
into three main regions: the epidermis, the dermis and the subcutaneous tissue [1] (Table 1). The epidermis, a layer rich in cells is composed mainly of keratinocytes, which are the most numerous cell types, which ultimately form the outer protective skin barrier to the environment [2]-[4]. Healthy skin is something pursued by society and some spend everything they can and can not achieve the best appearance and the mere appearance of age, separating from actual age, predicts important aspects of health and well-being [5].

There are two main processes that induce skin aging: intrinsic and extrinsic. Extrinsic aging is caused by environmental factors such as sun exposure, air pollution, smoking, and poor nutrition. Intrinsic aging reflects the genetic background and depends on time. Extrinsically aged skin is characterized by photo damage as wrinkles, pigmented lesions, patchy hypopigmentations, and actinic keratoses [6].

\section{Oxidative Stress}

The free radical or oxidative stress theory of aging proposes that the accumulation of oxidative cellular damage is a major contributor to the aging process and a key determinant of longevity of the species. In a study that investigated the aging species of sea urchin short life and extraordinary longevity, found that levels were lower oxidative damage and antioxidant activity was higher in cells or tissues of long-lived species compared with short-lived species [7]. Consistent with the predictions of the oxidative stress theory of aging, the results suggest that the negligible senescence is accompanied by a decrease in cellular accumulation of oxidative damage with age, and maintenance of antioxidant status and the activities of enzymes of proteasome may be important mechanisms to mitigate the damage [7].

There is substantial evidence showing that aging is associated with damage from free radicals represented by various reactive oxygen species (ROS) [7]-[9].

Two general features are responsible for the long lives on in some animals: a low generation rate of endogenous damage and the existence of highly resistant to oxidative modification tissue macromolecules [10]. Therefore the role of ROS in aging explains why animals with higher metabolic rate have lower life expectancy [11]. Aging is associated with changes in the molecular structure of DNA, proteins, the lipids, and prostaglandins. All are markers of oxidative stress, although all changes were not only because of oxidation, there are also other ways including spontaneous errors and other modifications of proteins [12]. The accumulation of these molecular changes, in particular proteins, forms the basis of cellular aging. However, it is also recognized that the production of ROS, which play a role in normal signaling processes, is essential to maintain homeostasis and cellular response [13].

The concept of the free radical theory of aging votes so far, it has been contradicted in some studies and today discussing infidelity, the heterogeneity and the imperfection of each biological process may be responsible for the inevitable accumulation by products and other forms of damage. Therefore, much remains to investigate this area [14].

The skin is also subject to an intrinsic aging process similar to the entire organins. The exogenous factors also influenced the skin aging. The extrinsic skin aging (photoaging) can be occurring by ultraviolet radiation causind premature skin aging. The formation of ROS can reflect the central aspects of skin aging. The detection of mechanisms of extrinsic factors in skin aging is important to the developer various therapeutics and preventive strategies [15].

The skin has a complex defense system to deal with harmful environmental and chemical substances but ex-

Table 1. Structure and function of skin: Epidermis, dermis and subcutaneous tissue.

\begin{tabular}{|c|c|c|c|}
\hline & \multicolumn{3}{|c|}{ Skin’s layers } \\
\hline & Epidermis & Dermis & Subcutaneous tissue \\
\hline Structure & $\begin{array}{l}\text { Superficial part of the skin; } \\
\text { stratified spamous epithelium; } \\
\text { composed of four of five strata. }\end{array}$ & $\begin{array}{l}\text { Deep part of skin; connective tissue } \\
\text { composed of two layers. }\end{array}$ & $\begin{array}{l}\text { NOT PART OF THE SKIN; loose } \\
\text { connective tissue with abundant } \\
\text { deposits of adipose tissue. }\end{array}$ \\
\hline Function & $\begin{array}{l}\text { Prevents water loss and the entry of } \\
\text { chemicals and microorganisms; } \\
\text { protects against abrasion and } \\
\text { ultraviolet light produces vitamin } \\
\text { D; gives rise to hair, nails, and } \\
\text { glands }\end{array}$ & $\begin{array}{l}\text { Is responsible for the structural } \\
\text { strength and flexibility of the skin; the } \\
\text { epidermis exchanges gases, nutrients, } \\
\text { and waste products with blood vessels } \\
\text { in the dermis. }\end{array}$ & $\begin{array}{l}\text { Attaches the dermis to underlying } \\
\text { structures; adipose tissue provides } \\
\text { energy storage, insulation, and padding; } \\
\text { blood vessels and nerves from the } \\
\text { subcutaneous tissue supply the dermis. }\end{array}$ \\
\hline
\end{tabular}


cessive or chronic exposure can overwhelm the system leading to oxidative stress and oxidative damage. These are superoxide radicals $\left(\mathrm{O}_{2}^{-}\right)$, hydrogen peroxide $\left(\mathrm{H}_{2} \mathrm{O}_{2}\right)$, and hydroxyl radical (-OH) [16].

During skin aging the effectiveness of endogenous antioxidant system is diminished [17] and ROS formation causes mainly DNA damage [18]. Oxidative stress due to aging process not only induces DNA damage, but also, intracellular lipid peroxidation, abnormal protein oxidation reactions, all of which result in cell damage [19], inflammation [20] [21], immune suppression [21], oxidative stress, hyperplastic responses in skin as well as perturbed hormonal balances [22], and premature skin aging [19].

The biological consequences of damage caused by stress oxidative and consequently in DNA damage are alteration in gene expression and consequently protein expression can be modified [20], blockage in RNA transcription [23], increased cell death, altered metabolic redox balance [24] [25], and defects on transcription through RNA polymerases I and II can occur [26].

The mechanism that can to explain the DNA damage in skin aging due oxidative stress is the potentially result in a blockage in DNA synthesis, as replicative DNA polymerases do not have the capacity to use damaged templates. This important blockage may lead to the collapse of the replication fork, production of double-strand breaks, and, ultimately, cell death [27].

These lesions, if not repaired in a timely manner, can cause severe structural distortions in the DNA molecule, thereby affecting important cellular processes such as DNA replication and transcription, and compromising cellular viability and functional integrity [28].

DNA damage can also change the proteins turnover because of the alterations in the DNA replication and transcriptions already related above. And for healthy and youth skin is necessary basement membrane (BM) be intact and functional to maintain normal protein synthesis. Some cosmetic ingredients also promote BM repair by increasing the synthesis of BM components, such as laminin 332, and type IV and VII collagens, in the epidermis and/or the dermis. Hence, BM represents a good target for skin-care products; components that enhance BM repair may improve epidermal-dermal communication and skin homeostasis, thereby strengthening defenses against "skin aging" [29].

Oxidative stress is one of the most important causes of the cellular senescence process. Previous studies showed that $\beta$-catenin can regulate FoxO3a and this association was enhanced in cells exposed to oxidative stress. It has also been reported that $\beta$-catenin can regulate some senescence-related proteins. It was demonstrated that $\beta$-catenin can protect normal human primary skin fibroblasts from $\mathrm{H}_{2} \mathrm{O}_{2}$-induced premature senescence by alleviating oxidative stress and regulating some senescence-related molecules [30].

Damage DNA due to high levels of ROS can develop genomic instability. And one protective response to increased levels of ROS is the induction of cellular senescence [31].

ROS can induce premature cellular senescence, which is believed to contribute to skin aging and age-related diseases. Inhibition of oxidant-induced activation of Nrf2-dependent signaling, promotes premature senescence, and inhibits their transformed phenotype. Thus, by inhibiting Nrf2-mediated signaling, caveolin-1 links free radicals to the activation of the p53/senescence pathway [32].

\section{Role of Mitochondria}

Mitochondria are producers and also targets of oxidative stress, forming the basis for the Mitochondrial Theory of Aging. Within the mitochondria an accumulation of somatic mitochondrial DNA mutations induced by exposure to ROS, which leads to errors in encoding polypeptides by mitochondrial DNA and the subsequent transfer activity and oxidative phosphorylation is defective occurs. Over the years, the activity of the mitochondrial respiratory system and its constituent enzymes such as cytochrome c oxidase in a range of tissues including skeletal muscle, heart and liver decreases, and therefore the integrity of the mitochondrial DNA is also reduced in these tissues [33] [34].

In the aging process, accumulation of mutations in mitochondrial DNA, decreased oxidative phosphorylation occurs as well as an imbalance in the expression of antioxidant enzymes results in greater overproduction of ROS. Mitochondrial dysfunction and ROS production leads to a vicious cycle which is the basis of mitochondrial free radical theory of aging. Moreover, several lines of evidence have recently emerged to show that ROS play a crucial role in the regulation of cell metabolism, antioxidant defense and post-translational modification of proteins. Some authors point out that there are positive roles and integrators mild oxidative stress caused by the mitochondria in the regulation of adaptation in anti-aging and cleansing way beyond their roles in the vicious cycle of mitochondrial dysfunction caused the aging process [35]. 
There are evidences that mitochondrial dysfunctions are involved in skin aging [36]. Mitochondria play crucial roles in several age-related diseases, and in the physiology of normal skin aging [37]. The effects of skin photodamage and aging are studied by the use of animal models [38].

There are studies with accelerated skin aging in mouse models. The senescence-accelerated mouse is a model for senescence acceleration, a higher oxidative stress status, and age-associated disorders. Chiba et al. (2005) studied whether fibroblasts cultured from accelerated senescence-prone SAMP11 mice could be used as in vitro models for oxidative stress in senescence. Therefore cells from SAMP11 mice are useful models for spontaneous higher oxidative stress in vitro due to dysfunctional mitochondria [39].

\section{Cellular Senescence and Telomeres}

The diploid cells exhibit a limited proliferation potential. One explanation for the cells reach this limit follows from the telomeres, which are repetitive DNA sequences present at the end of the linear DNA. Telomeres shorten a little every time the cell divides (about 50 - 200 bp per cell division). The shortening of telomere DNA inhibits cell division [40]. Conditions in premature aging of tissues from a given chronological age contains much closer to its limit of programmed cell division compared to those normal elderly individuals cells [40] [41]. Germline cells, stem cells or other normal diploid cells contain an enzyme called telomerase that replaces the lost telomere DNA during cell divisions. The ability to reverse cellular senescence in the exchange a copy of the gene encoding the catalytic subunit of telomerase in normal cells, to restore the activity of telomerase, has been considered [42]-[44]. This strategy can also increase the risk that the cells become immortalized. The theory of cellular senescence of aging has limitations because organs such as the brain, which consist primarily of cells that do not suffer divisions, but also age [45].

Skin is a self-renewing tissue that is required to go through extensive proliferation throughout the lifespan of an organism. Telomere shortening acts as a mitotic clock that prevents aberrant proliferation such as cancer. A consequence of this protection is cellular senescence and aging. The telomerase enzyme complex maintains telomere length in germline cells and in cancer cells. Telomerase is also active in certain somatic cells such as those in the epidermis but is almost undetectable in the dermis. Increasing evidence indicates that telomerase plays a significant role in maintenance of skin function and proliferation [46].

Cellular senescence is the irreversible growth arrest of individual mitotic cells, which as a consequence display a radically altered phenotype that is thought to impair tissue function and predispose tissues to disease development and/or progression as they gradually accumulate. Recent findings suggest that cellular senescence does contribute to skin aging and the development/progression of disease [47].

The predominant aging mechanism of mitotic tissues is thought to be due to the gradual accumulation of senescent cells. Senescent cells have undergone an irreversible cell cycle arrest, and display a radically altered phenotype: genetically, morphologically and behaviourally distinct from its growth-competent counterparts. These changes are thought to have a detrimental impact on neighbouring cells, the surrounding extracellular matrix and other structural components, leading to aged tissues, disease, and an increased risk of cancer [48]-[51].

Higher organisms contain two types of cells: postmitotic cells, which never divide, and mitotic (or mitotically competent) cells, which can divide. Postmitotic cells include mature nerve, muscle, and fat cells, some of which persist for life. Mitotic cells include epithelial and stromal cells of organs such as the skin. Because postmitotic and mitotic cells differ in their proliferative capacity, they may age by different mechanisms. Normal somatic mitotically competent cells do not divide indefinitely. The process that limits the cell division number is termed cellular or replicative senescence. Replicative senescence is thought to be a powerful, albeit imperfect, tumor suppressive mechanism. It is also thought to contribute to organismic aging [52].

Senescent cells undergo three phenotypic changes: they irreversibly arrest growth, they acquire resistance to apoptotic death, and they acquire altered differentiated functions. The growth arrest is very likely critical for the role of replicative senescence in tumor suppression, but may be less important for the aging of organs such as the skin. On the other hand, the altered differentiation may be critical for compromising the function and integrity of organs like the skin during aging. Senescent keratinocytes and fibroblasts appear to accumulate with age in human skin. Moreover, senescent cells express genes that have long-range, pleiotropic effects-degradative enzymes, growth factors, and inflammatory cytokines [52].

The skin has continuous renewal throughout an individual's lifetime; however, there is a decline in the regenerative potential of tissue with age. The accumulation of senescent cells over time probably reduces tissue re- 
generative capacity and contributes to the physiological aging of the tissue itself. The mechanisms that govern aging remain unclear and are under intense investigation, and insight could be gained by studying the mechanisms involved in cellular senescence [53].

In vitro, keratinocytes and dermal fibroblasts undergo senescence in response to multiple cellular stresses, including the overproduction of reactive oxygen species and the shortening of telomeres, or simply by reaching the end of their replicative potential (i.e., reaching replicative senescence). Recent findings demonstrate that microRN As play key roles in regulating the balance between a cell's proliferative capacity and replicative senescence [53].

Telomeres are DNA-protein complexes that cap chromosomal ends, promoting chromosome stability. Telomerase is a ribonucleoprotein complex with a direct telomere protective function. Telomere shortening represents lifetime exposure to oxidative stress and is negatively correlated with age, smoking, and mortality. Smoking increases oxidative DNA modification and thus may influence telomere dynamics and human telomerase reverse transcriptase (hTERT) activity [54].

Telomere length is a molecular marker of cell aging, and genomic instability due to telomere shortening has been linked to several aging-related diseases. It was suggest that telomere length in human dermal fibroblasts can be shortened by a single high dosage of UVA radiation, and that acute photodamage might contribute to early photoaging in human skin via rapid telomere shortening [55].

How it was discussed in previous sessions, elevation in ROS and dysfunctional mitochondria are closely associated with senescence cells. And the aging of organisms is characterized by a gradual functional decline of all organ systems. Mammalian somatic cells in culture display a limited proliferative life span, at the end of which they undergo an irreversible cell cycle arrest known as replicative senescence. Whether cellular senescence contributes to organismal aging has been controversial. Herbig and coworkers (2006) investigated telomere dysfunction, a recently discovered biomarker of cellular senescence, and found that the number of senescent fibroblasts increases exponentially in the skin of aging baboons, reaching $>15 \%$ of all cells in very old individuals. In addition, the same cells contain activated ataxia-telangiectasia mutated kinase and heterochromatinized nuclei, confirming their senescent status [56].

In addition, cellular senescence can also be induced by a number of environmental stresses and signaling imbalances which are independent of telomere shortening. The cyclin dependent kinase inhibitors p21 and p16 (INK4a) have been shown to execute and maintain the cell cycle arrest in senescence but the nature of the signals that cause upregulation of these inhibitors in senescent cells are only now starting to be discovered and is proposed a model that shows independent signals activate distinct signaling pathways to regulate p21 and p16 (INK4a) levels in senescent cells [56].

Common features of the senescent phenotype, which can potentially be detrimental to the tissues in which they reside, are the up-regulation of growth factors, extracellular matrix (ECM)-degrading proteins and pro-inflammatory cytokines [57] [58]. Why senescent cells adopt this phenotype is currently unknown. One possibility is that the senescent cell secretes cytokines to attract immune cells to its location (for its removal), secretes matrix degrading proteins to allow the immune cells access and secrete growth factors to stimulate surrounding cells to proliferate once the cell has been removed. This process may be effective in young organisms, but may gradually decline with age. Since immune cells are also governed by the ageing process, the removal of senescent cells may gradually become impaired. This would lead to the accumulation of senescent cells in tissues, causing detrimental alterations to the structure and consequently the function of those tissues [47].

\subsection{Apoptosis}

It is suggested that aging is associated mainly with hyper-regulation of apoptosis. However, it is unclear whether the age-related changes in the mechanism of apoptosis are a result of genetic programming or aging processes, such as oxidative stress [59] [60].

P53 is known to suppress tumors, but can also affect other aging processes not associated with tumor suppression. As a transcription factor, p53 responds to a number of stresses or inducing apoptosis (cell death) or cell cycle arrest (preservation of cells) to suppress tumor development. However, p53 has no effect on the aging aspects of cancer that is complicated and poorly understood. On one hand, p53 can induce cellular senescence or apoptosis to suppress cancer, but as an unintended consequence of the aging process better, especially if these responses diminish stem and progenitor cell populations. On the other hand, p53 could reduce the growth and stress-related growth to allow cell survival and ultimately slow the aging process. Therefore, a better under- 
standing of the diverse functions of p53 is essentially to elucidate their influences on the aging process and the possibility of targeting p53 or p53 transcriptional targets to treat cancer and relieve the general aging [61].

JNK and p38 belong to the family of stress kinases and have been shown to be required for biological stress responses, such as apoptosis induced by UV, radiation, oxidative stress, heat shock, and tumor necrosis factor (TNF)-stimulation. It has been reported that $\mathrm{H}_{2} \mathrm{O}_{2}$ signaling through TNF receptor 1 selectively activates JNK and p38 [62] [63].

Induction of DNA damage by UVB and UVA radiation may generate mutations and genomic instability leading to carcinogenesis. Therefore, skin cells being repeatedly exposed to UV light have acquired multilayered protective mechanisms to avoid malignant transformation. Besides extensive DNA repair mechanisms, the damaged skin cells can be eliminated by induction of apoptosis, which is mediated through the action of tumor suppressor p53. In order to prevent the excessive loss of skin cells and to maintain the skin barrier function, apoptotic pathways are counteracted by anti-apoptotic signaling including the AKT/mTOR pathway. However, AKT/mTOR not only prevents cell death, but is also active in cell cycle transition and hyper-proliferation, thereby also counteracting p53. In turn, AKT/mTOR is tuned down by the negative regulators being controlled by the p53. This inhibition of AKT/mTOR, in combination with transactivation of damage-regulated autophagy modulators, guides the p53-mediated elimination of damaged cellular components by autophagic clearance. Alternatively, p53 irreversibly blocks cell cycle progression to prevent AKT/mTOR-driven proliferation, thereby inducing premature senescence. Conclusively, AKT/mTOR via an extensive cross talk with p53 influences the UV response in the skin with no black and white scenario deciding over death or survival [64].

\subsection{Diet}

The skin reflects the health status of aging in general. The nutrition and its effects on the skin has always been an interesting topic for scientists and physicians for centuries worldwide. Vitamins, carotenoids, tocopherols, flavonoids and extracts from a variety of plants seem to possess potent antioxidant properties and have been widely used in the skin care industry or as an agent applied topically or oral supplements in an attempt to prolong the appearance of young skin. Thus, nutrition and skin aging are closely related [65].

The role of diet in skin aging is highly controversial, with limited scientific data available. Today we know the role of nutrition, glycation and oxidation in aging skin [66].

Further, caloric restriction prolongs life in yeast, Drosophila, worms, rodents and primates, probably. Despite the extensive work that demonstrates the effectiveness of calorie restriction, the mechanism by which prolongs life is unclear. One hypothesis is that it slows the metabolism and consequently the production of ROS [67].

Improvements in health care have increased human life expectancy in recent decades, and the elderly population is thus increasing in most developed countries. Unfortunately this still means increased years of poor health or disability. Since it is not yet possible to modify our genetic background, the best anti-aging strategy is currently to intervene on environmental factors, aiming to reduce the incidence of risk factors of poor health. Calorie restriction (CR) with adequate nutrition is the only non-genetic, and the most consistent non-pharmacological intervention that extends lifespan in model organisms from yeast to mammals, and protects against the deterioration of biological functions, delaying or reducing the risk of many age-related diseases. The biological mechanisms of CR's beneficial effects include modifications in energy metabolism, oxidative stress, insulin sensitivity, inflammation, autophagy, neuroendocrine function and induction of hormesis/xenohormesis response [68].

The molecular signalling pathways mediating the anti-aging effect of CR include sirtuins, peroxisome proliferator activated receptor G coactivator- $1 \alpha$, AMP-activated protein kinase, insulin/insulin growth factor-1, and target of rapamycin, which form a pretty interacting network. However, most people would not comply with such a rigorous dietary program; research is thus increasingly aimed at determining the feasibility and efficacy of natural and/or pharmacological CR mimetic molecules/treatments without lowering food intake, particularly in mid- to late-life periods. Likely candidates act on the same signalling pathways as CR, and include resveratrol and other polyphenols, rapamycin, 2-deoxy-D-glucose and other glycolytic inhibitors, insulin pathway and AMP-activated protein kinase activators, autophagy stimulators, alpha-lipoic acid, and other antioxidants [68].

Recent evidence supports the contention that cellular senescence is associated with, and may even be a cause of age-related functional impairment. The presence of senescent cells might therefore be a contributing factor to aging [69]. Cellular senescence causes a variety of cell types to acquire a pro-inflammatory secretory phenotype that produce a variety of cytokines, chemokines, and extracellular matrix remodeling proteases that are asso- 
ciated with tissue destruction [70]-[72]. Chronic presence of senescent cells can accelerate cancer progression, possibly because of this inflammatory secretory phenotype [73] [74].

Engineered deposition of senescent cells in a single organ, skin, can cause functional impairments in multiple organs similar to those occurring with aging [75]. Finally, senescent cell accumulation in progeroid animal models is associated with dysfunction resembling that of aging [76]. Caloric restriction attenuates processes that have been implicated in cellular senescence, including generation of ROS, growth hormone/insulin-like growth factor-1 signaling, and inflammation [77] [78].

In an important study in this journal, Wang et al. found short term dietary restriction in middle-aged mice is associated with decreased abundance of senescent cells in the liver (centrilobular hepatocytes) and intestine (crypt enterocytes) [79].

Increment of subcutaneous adipose tissue is a risk factor for facial morphological changes, such as sagging, which may be at least partly because of the increased weight burden of accumulated fat. However, it is not clear how the increase of subcutaneous adipose tissue affects dermal structure and function. We examined this issue in HR-1 hairless mice given ahigh-fat diet (HFD). After having been fed with HFD for 12 weeks, the mice became obese and the subcutaneous adipose tissue layer was significantly thickened, while the dermal layer became significantly thinner than that of control mice fednormal diet. However, the thickness of the dermal layer was not changed in the ear pinna, which lacks a subcutaneous adipose layer, suggesting that increase of subcutaneous adipose tissue may induce dermal changes [80].

The number of dermal fibroblasts in the dermis was significantly reduced in obese mice, although there was no change in gene expression levels of extracellular matrix components, including collagen, hyaluronic acid synthase, fibulin 5, fibrillin-1, laminin $\beta 1$, matrix metalloproteinases and tissue inhibitor of metalloproteinases. Dermal elasticity was significantly decreased in obese hairless mice. Subcutaneous adipose cells in obese mice may reduce the proliferation of dermal fibroblasts and induce a decrease of dermal thickness and elasticity. Therefore, the increment of the subcutaneous adipose layer in obese subjects may induce impairment of dermal biomechanical characteristics and promote the appearance of sagging [80].

Apolipoprotein E knockout (apoE-KO) mice have been utilized for decades as a model of atherosclerosis. However, in addition to atherosclerosis, apoE-KO mice develop extensive cutaneous xanthomatosis, accelerated skin aging and frailty when fed a high fat diet. Granzyme B $(\mathrm{GrB})$ is a pro-apoptotic serine protease that has recently been shown to exhibit extracellular proteolytic activity in certain pathologies [81].

Hiebert and collaborators (2011) was studied the role of GrB in skin aging and pathology was assessed using the apoE-KO model of skin aging. Male C57BL/6 wild type and apoE-KO mice were grown for $0,5,15$ or 30 weeks on either a high fat $(21.2 \%$ fat, $0.2 \%$ cholesterol) or regular chow diet ( $7 \%$ fat). ApoE/GrB double knockout (DKO) mice were also generated and assessed after being fed either diet for 30 weeks. Skin was removed from the mid to lower back and examined for age-related changes such as hair loss, skin thinning and collagen remodeling and disorganization. ApoE-KO miceexhibited signs of frailty, hair graying, hair loss, skin thinning, loss of collagen density and increased skin pathologies featuring collagen remodeling and reduced decorin compared to wild type controls. These phenotypes occurred earlier and were more severe when fed a high fat diet. In addition, the authors also observed increased GrB expression in proximity to areas of decorin degradation and reduced collagen density in the skin of apoE-KO mice. DKO mice exhibited protection against skin thinning, ECM degradation and loss of dermal collagen density [81].

Identifying factors that accelerate the aging process can provide important therapeutic targets for slowing down this process. Misregulation of phosphate homeostasis has been noted in various skeletal, cardiac, and renal diseases, but the exact role of phosphate toxicity in mammalian aging is not clearly defined. Phosphate is widely distributed in the body and is involved in cell signaling, energy metabolism, nucleic acid synthesis, and the maintenance of acid-base balance by urinary buffering [82].

Ohnishi \& Razzaque in 2010 used an in vivo genetic approach to determine the role of phosphate toxicity in mammalian aging. Klotho-knockout mice (klotho(-l-)) have a short life span and show numerous physical, biochemical, and morphological features consistent with premature aging, including kyphosis, uncoordinated movement, hypogonadism, infertility, severe skeletal muscle wasting, emphysema, and osteopenia, as well as generalized atrophy of the skin, intestine, thymus, and spleen. Molecular and biochemical analyses suggest that increased renal activity of sodium-phosphate cotransporters (NaPi2a) leads to hyperphosphatemia that was induced in mice by feeding with a high-phosphate diet, premature aging-like features reappeared, clearly suggesting that phosphate toxicity is the main cause of premature aging in klotho(-/-) mice. This dietary and genetic 
manipulation studies provide in vivo evidence for phosphate toxicity accelerating the aging process and suggest a novel role for phosphate in mammalian aging [82].

Aging is accelerated, at least in part, by pathological condition such as metabolic syndrome (MetS), and various molecular pathways such as oxidative stress are common mediators of aging and MetS. Nagase and coworkers (2013) were previously developed the aging-like skin model by single ultraviolet (UV) irradiation on the MetS model mice. Recent studies revealed that mineralocorticoid receptor (MR) signaling plays a pivotal role for various tissue inflammation and damages in MetS. Although previous studies reported that MR is expressed in the skin and that overexpression of MR in the skin resulted in the skin atrophy, the physiological or pathological functions of MR in the skin are not fully elucidated. These authors showed the involvement of MR signaling in the aging-like skin changes in their model. Elevations of oxidative stress and inflammation markers were observed in the MetS mice, and the UV-evoked aging-like skin damages were attenuated by topical antioxidant. MR expression was higher in the MetS mouse skin, and notably, expression of its effecter gene Sgk1 was significantly upregulated in the aging-like skin in the UV-irradiated MetS mice. Furthermore, topical application of MR antagonist spironolactone suppressed Sgk1 expression, oxidative stress, inflammation, and the aging-like changes in the skin. The 2-week UV onto the non-MetS mice, the more usual photoaging model, resulted in the skin damages mostly equivalent to the MetS mice with single UV, but they were not associated with upregulation of MR signaling. This study suggested an unexpected role of MR signaling in the skin aging in MetS status [83].

\subsection{Genetics}

The role of genetically programmed aging is controversial and there is evidence for a key role for the genetic program that includes observations that the lifespan of a species is relatively fixed and human aging that have a heritable component [84]. In addition, individual mutations in humans can cause premature aging syndromes and altered expression of single genes that can increase the maximum lifespan in lower organisms [85]. However, a rational evolution principle makes possible the determination of genetic aging is less likely. Some genes influence longevity through responses to the underlying aging processes or susceptibility to disease [85]. The aging is associated with altered gene expression; however, still, DNA studies did not identify any unexpected change in old age [84].

Ageing is associated with a general progressive loss of skin integrity, significant inter-individual differences exist [86].

Laminopathies, due to mutations in LMNA, encoding A type-lamins, can lead to premature aging and/or lipodystrophic syndromes, showing that these diseases could have close physiopathological relationships. We show here that lipodystrophy and extreme insulin resistance can also reveal the adult progeria Werner syndrome linked to mutations in WRN, encoding a RecQ DNA helicase. Waaijer and collaborators in 2012 showed the first time that partial lipodystrophy with severe insulin resistance can reveal WRN-linked premature aging syndrome. Increased expression of lamin B1 with altered lamina architecture observed in WRN-mutated fibroblasts could contribute to premature cellular senescence. Primary alterations in DNA replication and/or repair should be considered as possible causes of lipodystrophic syndromes [86].

\subsection{Effects of Ultraviolet Light}

The influence of the environment, called solar UV irradiation, is of considerable importance to skin aging [87]. Historically, photoaging and chronological skin aging were considered separate entities. Although the typical appearance of photo-aged human skin or chronological effect can be easily distinguished, recent evidence indicates that parts of chronologically aged skin or irradiated with UV has major changes in molecular characteristics, including the transduction signaling pathways that promote expression matrix metalloproteinase, a decrease in pro-collagen synthesis and tissue damage [87]. The stress plays a central role in the signaling events which initiate and conduct the cellular response after UV irradiation. The UV irradiation of the skin increases the hydrogen peroxide and other ROS and decreases anti-oxidant enzymes. These characteristics are also observed in chronologically aged human skin. In both cases, increased ROS production genes alter the structure and function of proteins that lead to skin damage. This suggests that UV irradiation accelerates many key aspects of the chronological aging process in human skin. Based on this relationship between UV Irradiance and chronological aging, acute UV irradiation of human skin may serve as a useful tool to study the molecular mechanism of 
chronological aging of the skin [88].

Recent studies have suggested that intrinsic aging and photoaging share a common pathway involving telomere-generated signaling that is responsible for most clinical manifestations of skin aging [89]-[91]. However, an earlier study showed that telomere length did not differ significantly between sunexposed and sun-protected skin [92] [93]. Thus, whether the length of telomere is shortened in photoaging remains unclear.

\section{Effects of Smoking}

Tobacco smoke released into the environment has a drying effect on the the surface of the skin and reduces the amount of blood flowing to the skin, thus depleting the skin of oxygen and essential nutrients [94]. Smokers in their $40 \mathrm{~s}$ often have as many facial wrinkles similar to non-smokers in their $60 \mathrm{~s}$. In addition to facial wrinkles, smokers may develop hollow cheeks through repeated drawing of cigarettes, which is particularly noticeable in smokers underweight, resulting in a skeletal appearance. The skin of smokers may be prematurely aged between 10 and 20 years and although the harmful effects of cigarette smoke on your skin are irreversible, further deterioration can be avoided with the cessation of smoking [95].

Although it is now widely recognized that tobacco smoke has negative effects on the skin, the molecular mechanisms underlying its skin-aging effects remain uncertain. Epidemiological studies indicate that tobacco smoking is a strong independent predictor of facial wrinkle formation and other aspects of premature skin aging. Recent in vivo studies in humans and mice provided the first direct evidence that tobacco smoke causes premature skin aging and they have begun to reveal the molecular changes in the skin that occur in response to it. Water-soluble tobacco smoke extract, which predominantly produces oxidative stress when applied topically to cultured skin fibroblasts, impairs collagen biosynthesis. Matrix metalloproteinases, which degrade collagen, are induced dose-dependently by tobacco smoke extract as well as by other constituents that trigger the aryl hydrocarbon receptor (AhR), a ligand-dependent transcription factor that mediates the toxicity of several environmental contaminants, including photoproducts in the body generated by UVB radiation. Tobacco smoke also contains many non-water-soluble constituents that activate the AhR pathway. Recent studies using hexane-soluble tobacco extract indicate that activation of the AhR pathway may play a role in the premature skin-aging effects of tobacco smoke exposure [96].

Findings from large epidemiologic studies indicate that there is a link between smoking and extrinsic skin aging. We previously reported that matrix metalloproteinases (MMPs) mediate connective tissue damage in skin exposed to tobacco smoke extracts. Tobacco smoke contains more than 3800 constituents, including numerous water-insoluble polycyclic aromatic hydrocarbons (PAHs) that trigger aryl hydrocarbon receptor (AhR) signalling pathways. To analyse the molecular mechanisms involved in tobacco smoke-induced skin aging [97].

In a previous study were exposed primary human fibroblasts and keratinocytes to tobacco smoke extracts. Hexane- and water-soluble tobacco smoke extracts significantly induced MMP-1 mRNA in both human cultured fibroblasts and keratinocytes in a dose-dependent manner. To clarify the involvement of the AhR pathway, we used a stable AhR-knockdown HaCaT cell line. AhR knockdown abolished the increased transcription of the AhR-dependent genes CYP1A1/CYP1B1 and MMP-1 induced by either of the tobacco smoke extracts. Furthermore, the tobacco smoke extracts induced 7-ethoxyresorufin-O-deethylase activity, which was almost completely abolished by AhR knockdown. Likewise, treating fibroblasts with AhR pathway inhibitors, that is, the flavonoids 3-methoxy-4-nitroflavone and $\alpha$-naphthoflavone blocked the expression of CYP1B1 and MMP-1. These findings suggest that the tobacco smoke extracts induce MMP-1 expression in human fibroblasts and keratinocytes via activation of the AhR pathway. Thus, the AhR pathway may be pathogenetically involved in extrinsic skin ageing [97].

\section{Pollution}

Skin cancer is continuously increasing as well as the majority of deaths due to skin melanoma [98]. The most common skin cancers are basal cell carcinoma (76\%), squamous cell carcinoma (19\%) and melanoma (5\%). Skin cancers are more closely associated, although not exclusively, the exposure of ultraviolet B radiation (UV-B). The depletion of the ozone layer of the earth exacerbate genetic damage and environmental pollution from the combustion of fossil products is a major concern for all medical areas, it is predicted that the ozone layer will remain decreased for decades, even after these pollutants are replaced by products not depletem the ozone layer [99]. 
Despite its barrier properties of the skin is also a point of entry for substances capable of causing damage, for example, exposure to xenobiotics, pesticides, cosmetics and topical medicines [100]. Percutaneous exposure is needed to determine its importance in the absorption of many materials, as well as strengthening measures to protect against exposure to hazardous chemicals [100].

Living organisms are continuously exposed to environmental pollutants. Because of its critical location, the skin is a major interface between the body and the environment and provides a biological barrier against an array of chemical and physical environmental pollutants. The skin can be defined as our first defense against the environment because of its constant exposure to oxidants, including UV radiation and other environmental pollutants such as diesel fuel exhaust, cigarette smoke (CS), halogenated hydrocarbons, heavy metals, and ozone $\left(\mathrm{O}_{3}\right)$. The exposure to environmental pro-oxidant agents leads to the formation of ROS and the generation of bioactive molecules that can damage skin cells [101].

Extrinsic skin aging is the skin aging process induced by environmental factors. The most prominent environmental factor leading to extrinsic skin aging is the sun; therefore extrinsic skin aging is also known as photoaging. However, numerous studies in recent years have shown that smoking leads also to extrinsic skin aging. Further, very recently it has been shown, that environmental pollution by traffic is also associated with the occurrence of signs of extrinsic skin aging. Thus, in preventive skin aging strategies the long-term exposure towards air pollution by traffic must also be considered [102].

\section{Intracellular Signaling and Skin Lesions}

The earliest detectable response to UV irradiation on the skin is the activation of cytokine receptors and cellsurface growth factor, including epidermal growth factor (EGF-R) factor receptor, TNF-receptor, factor receptor platelet-activating (PAF), the insulin receptor, the interleukin (IL)-1 and the derived growth factor (PDGF) [103]. The activation of cytokine cell surface receptors results in the recruitment of adapter proteins that mediate downstream signaling.

The combination of these complex signaling causes the activation of GTP-binding proteins, key regulators of MAP kinases. The action of certain GTP-binding proteins results in an increase in superoxide. This increase in ROS production participates in the amplification of the signal leading to the activation of downstream enzyme complexes. ROS are necessary participants in the multiple MAP kinase pathways [104]. Increasing content of intracellular ceramide induced by UV can also contribute to the activation of MAP kinase pathways. The generation of UV-induced ceramide seems to be dependent on increased production of ROS and the levels of ceramide and rise together and ROS production induced by UV ceramide is inhibited by vitamin E [105]. The results of the activation of the MAP kinase pathway in the induction of transcription factor AP-1 alters the expression of many genes involved in the regulation of cell growth and differentiation. AP-1 tightly regulates the transcription of various MMPs (matrix metalloproteinases) [106].

The previous sections have been effectors of skin ageing where this section appears to be the consequence. This needs to be clarified.

Cytokines and growth factors, in addition to activation of MAP kinases and an elevation on ROS are features of cell senescence and should be discussed.

\subsection{Age-Related Diseases, Disorders, and Conditions of the Skin}

Oxidative stress has been indicated in a variety of pathological processes, such as atherosclerosis, diabetes, neurodegenerative diseases, and aging. ROS induce DNA damage, intracellular lipid peroxidation, and abnormal protein oxidation reactions, all of which result in cell damage [107].

Mitochondrial DNA damage has been used as a successful and unique biomarker of tissue stress. A valuable example of this is sun damage in human skin which leads to aging and skincancer. The skin is constantly exposed to the harmful effects of sunlight, such as UV radiation, which causes it to age with observable characteristic features as well as clinical precancerous lesions and skin cancer. Formation of free radicals by the sun's harmful rays which contribute to oxidative stress has been linked to the induction of deletions and mutations in the mitochondrial DNA. These markers of mitochondrial DNA damage have been proposed to contribute to the mechanisms of aging in many tissues including skin and are associated with many diseases including cancer [108].

Skin is frequently exposed to a variety of environmental, chemical, and genotoxic agents that contribute to 
disease and carcinogenesis. UV light is the main external stress that leads to immunosuppression, oxidative stress, premature aging, and tumor formation. Scientists and health professionals emphasize the importance of prevention strategies to circumvent such unfavorable outcomes. Plant polyphenols are a promising approach to disease prevention and treatment. Green tea is an abundant source of plant polyphenols that exhibit significant antioxidant, chemopreventive, and immunomodulatory effects in protecting the skin [109].

As the incidence of skin tumors has been steadily growing, there is an urgent need for the preventive measures as well as the improved therapeutic approaches. In the last two decades, natural plant derived polyphenols (PPs, resveratrol, silibinin, green tea polyphenols, flavonoids, anthocyanins, etc.) have been drawing particular interest as emerging active substances in dermatological/cosmeceutical compositions for the prevention, slowing, or reversion of skintumorigenesis (chemoprevention). When chronically applied to the skin, they supposedly would not damage normal skin cells or negatively affect their functions while they would suppress tumorigenic cell transformation, inhibit tumor cell proliferation, and activate tumor cell apoptosis. PPs are also reported to synergize with conventional anti-cancer therapies [110].

Korkina et al. in 2012 provided recent updates on the molecular and cellular targets for the prevention and therapy of skin tumors with a special focus on the crossroad between inflammation and carcinogenesis as the most promising approach to chemoprevention. Novel therapeutic targets as different as epidermal stem cells, cellular senescence, epigenetic enzymes involved in carcinogenesis, epidermal growth factor and aryl hydrocarbon receptors, and metabolic CYP1 subfamily enzymes are highlighted. The feasibility of PPs to prevent/cure specific cutaneous toxicity connected to anti-EGFR therapy and to reduce multidrug resistance of skin tumors is also discussed [110].

This contribution will address the effect of aging on skin functions, with a particular focus on skin permeability, wound healing, angiogenesis, lipogenesis, sweat production, immune function, and vitamin D synthesis. With accelerating age, skin functions deteriorate due to structural and morphologic changes. Skin is prone to the development of several diseases, varying from benign to malignant. Because the number of persons aged 80 and older is expected to rise in the next decades, disease prevention will become an important issue. Screening examinations and prevention through public education starting at an early age regarding sun avoidance, the use of sunscreens and the importance of a balanced nutrition are the first steps for successful healthyaging. Although the fundamental mechanisms in the pathogenesis of aged skin are still poorly understood, a growing body of evidence points toward the involvement of multiple pathways. Recent data obtained by expression profiling studies and studies of progeroid syndromes illustrate that among the most important biologic processes involved in skin aging are alterations in DNA repair and stability, mitochondrial function, cell cycle and apoptosis, extracellular matrix, lipid synthesis, ubiquitin-induced proteolysis and cellular metabolism. Among others, a major factor that has been implicated in the initiation of aging is the physiologic decline of hormones occurring with age. However, hormones at age-specific levels may regulate not only age-associated mechanisms but also tumor suppressor pathways that influence carcinogenesis. Understanding the molecular mechanisms of aging may open new strategies to deal with the various diseases accompanying high age, including cancer [111].

Recently, several important findings on melanoma development and progression have accelerated progress towards a molecular understanding of melanoma biology. Furthermore, the development of experimental tools, such as a wide range of cell lines and animal models of metastasis, has turned melanoma into a model for general tumour research. However, it has also become evident that melanoma is distinct from other tumours with regard to its cellular origin and pathophysiological mechanisms [112].

Basal cell carcinoma (BCC) of the skin, the most common malignancy in individuals of mixed European descent, is increasing in incidence due to an aging population and sun exposure habits. The realization that aberrant activation of Hedgehog signaling is a pathognomonic feature of BCC development has opened the way for exciting progress toward understanding BCC biology and translation of this knowledge to the clinic. Genetic mouse models closely mimicking human BCCs have provided answers about the tumor cell of origin, and inhibition of Hedgehog signalingis emerging as a potentially useful targeted therapy for patients with advanced or multiple BCCs that have hitherto lacked effective treatment [113].

Recent advances in skin-resident adult stem/progenitor cell research have revealed that these immature and regenerative cells with a high longevity provide critical functions in maintaining skin homeostasis and repair after severe injuries along the lifespan of individuals. The establishment of the functional properties of distinct adult stem/progenitor cells found in skin epidermis and hair follicles and extrinsic signals from their niches, which are deregulated during their aging and malignant transformation, has significantly improved our under- 
standing on the etiopathogenesis of diverse human skin disorders and cancers. Particularly, enhanced UV radiation exposure, inflammation and oxidative stress and telomere attrition during chronological aging may induce severe DNA damages and genomic instability in the skin-resident stem/progenitor cells and their progenies. These molecular events may result in the alterations in key signalling components controlling their self-renewal and/or regenerative capacities as well as the activation of tumour suppressor gene products that trigger their growth arrest and senescence or apoptotic death. The progressive decline in the regenerative functions and/or number of skin-resident adult stem/progenitor cells may cause diverse skin diseases with advancing age. Moreover, the photoaging, telomerase re-activation and occurrence of different oncogenic events in skin-resident adult stem/progenitor cells may also culminate in their malignant transformation into cancer stem/progenitor cells and skin cancer initiation and progression. Therefore, the anti-inflammatory and anti-oxidant treatments and stem cell-replacement and gene therapies as well as the molecular targeting of their malignant counterpart, skin cancer-initiating cells offer great promise to treat diverse skin disorders and cancers [114].

Discovery of novel drugs, treatments, and testing of consumer products in the field of dermatology is a multi-billion dollar business. Due to the distressing nature of many dermatological diseases, and the enormous consumer demand for products to reverse the effects of skin photodamage, aging, and hair loss, this is a very active field. Inflammatory and autoimmune skin diseases are all represented by a range of mouse models both transgenic and normal. Skin cancer is mainly studied in mice and fish. Wound healing is studied in a wider range of animal species, and skin infections such as acne and leprosy also have been studied in animal models. Moving to the more consumer-oriented area of dermatology, there are models for studying the harmful effect of sunlight on the skin, and testing of sunscreens, and several different animal models of hair loss or alopecia [38].

\subsection{Role of Androgens in Skin Aging}

Oestrogen (17 $\beta$ estradiol) and the dietary antioxidants resveratrol, genistein and S-equol, an isoflavone produced from the gut biotransformation of soy daidzein, are effective agents to reduce aging in skin. It is widely held that these antioxidants scavenge free radicals to prevent skindamage. However, the evidence to date suggests that the primary mechanism of action of these antioxidants is to activate oestrogen receptor $\beta(\operatorname{ER} \beta)$, which in turn enhances the expression of antioxidant enzymes and inhibits the expression of snail, a transcription factor that regulates keratinocyte cell proliferation and migration. Based on their selectivity, ER $\beta$ agents provide a treatment option for ageing skin without the potential safety issues associated with oestrogen therapy [115].

The links between hormonal signalling and lifespan have been well documented in a range of model organisms. For example, in C. elegans or D. melanogaster, lifespan can be modulated by ablating germline cells, or manipulating reproductive history or pregnenolone signalling. In mammalian systems, however, hormonal contribution to longevity is less well understood. With increasing age human steroid hormone profiles change substantially, particularly following menopause in women. Estrogen, which substantially decreases with advancing age in both males and females, protects against multiple aspects of cellular aging in rodent models, including oxidative damage, telomere shortening and cellular senescence. Estrogen's effects are particularly pronounced in the skin where cutaneous changes post-menopause are well documented, and can be partially reversed by classical Hormone Replacement Therapy (HRT) (Emmerson \& Hardman, 2012). These authors show that while chronological aging has clear effects on skin wound healing, falling estrogen levels are the principle mediator of these effects. Thus, both HRT and topical estrogen replacement substantially accelerate healing in elderly humans, but are associated with unwanted deleterious effects, particularly cancer promotion. In fact, much current research effort is being invested in exploring the therapeutic potential of estrogen signalling manipulation to reverse age-associated pathology in peripheral tissues. In the case of the skin the differential targeting of estrogen receptors to promote healing in aged subjects is a real therapeutic possibility [116].

Estrogen deficiency following menopause results in atrophic skin changes and acceleration of skin aging. Estrogens significantly modulate skin physiology, targeting keratinocytes, fibroblasts, melanocytes, hair follicles and sebaceous glands, and improve angiogenesis, wound healing and immune responses. Estrogen insufficiency decreases defense against oxidative stress; skin becomes thinner with less collagen, decreased elasticity, increased wrinkling, increased dryness and reduced vascularity. Its protective function becomes compromised and aging is associated with impaired wound healing, hair loss, pigmentary changes and skin cancer. Skin aging can be significantly delayed by the administration of estrogen. The relevance of estrogen replacement, selective es- 
trogen receptor modulators (SERMs) and phytoestrogens as therapies for diminishing skin aging is highlighted. Understanding estrogensignaling in skin will provide a basis for interventions in aging pathologies [117].

\subsection{Advanced Glycation End Products (AGEs) in Skin Aging}

Skin is affected by the aging process and numerous modifications are observed. In human, with time the skin becomes drier, thinner, spots appear, elasticity decreases and stiffening increases, together with the appearance of wrinkles. These observations result from the overlapping of an intrinsic chronological aging (individual, genetic) and of an extrinsic aging (dependent on external factors like UV, pollution and lifestyle). One of the causes of aging is the appearance of the Advanced Glycosylation End Products (AGEs) during life. The glycation reaction results from a non-enzymatic reaction between a sugar and a free amine group of Lys, Arg amino acids in proteins. This reaction does not occur only in the skin, indeed, AGEs are also found in the kidney, lens, vessels, etc. These products are also responsible, because of their localization, of some pathology related to diabetes. AGEs provoke biological modifications implying an activation of molecules synthesis (extracellular matrix, cytokines) and enzyme activation of matrix degradation (metalloproteinases). The UV effect on AGEs (like pentosidine) generates reactive oxygen species (ROS) in the extracellular matrix which could lead to additional deleterious effects. Molecules are described in the literature as inhibitors to this irreversible reaction i.e. aminoguanidine. To understand the consequences of the glycation in the skin, a system of reconstructed skin was developed with a collagen modified by glycation for the dermal component. In this system we observed that dermis and epidermis are both modified due to glycation (macromolecules synthesis, cytokines, and metalloproteinases) and it is possible to test inhibitors of this reaction. In skin, glycation is involved in a very complex aging process and simultaneously affect, directly and indirectly, certain cells, their synthesis and the organization of the matrix [118].

To meet the growing need for tissue replacement materials for our aging population, the development of new adaptive biomaterials is essential. The tissues with the highest demand for implant materials are skin and bone. These tissues share various similarities, including signaling pathways and extracellular matrix composition. Glycosaminoglycans such as hyaluronan and chondroitin sulfate are the major organic extracellular matrix components. They modulate the attraction of skin and bone precursor cells and their subsequent differentiation and gene expression and regulate the action of proteins essential to bone and skin regeneration. The precise action of glycosaminoglycans varies according to their structural composition mainly in respect to the degree of sulfation and polymer length. Changes in the glycosaminoglycan composition are frequently seen in physiological and pathological remodeling processes, such as bone formation or scaring [119].

Skin aging is a combination of natural aging with superimposed photoaging. Naturally aged skin is thin, fragile and finely wrinkled whereas photoaged skin is rough and thickened with deep coarse wrinkles. In addition photoaging is characterized by mottled pigmentation, solar lentigines, telangectasias and a loss of elasticity. The science behind skin aging has exploded in the past decade. Skin aging has now been defined on both a cellular and molecular level. The study of genomics in aging skin provides us with potential targets as points for intervention. In this regard, the science behind skin aging becomes a platform for the development of new anti-aging strategies and products. Sirtuin activating and anti-glycation products are already being marketed by cosmetic and pharmaceutical companies. These anti-aging approaches are backed by basic science research and the ingredients used are supported by proof of concept studies although clinical trials are often lacking. It is this bench to beauty counter approach to cosmeceuticals that remains an industry standard today [120].

The naturally occurring molecules $\mathrm{N}$-acetylcarnosine, L-carnosine, and carcinine, which are chemical or pharmacological chaperones, affect the cells and biomolecules of patients with skin diseases, cosmetic skin lesions, or underlying clinically significant visual impairment such as age-related cataracts, age-related retinal degeneration, and ocular complications of diabetes. We evaluated and characterized the effects of cited pharmacological chaperones on enzyme activity, protein structure in tissues, and other biomarkers of diseases in skin cells and tissues or in ocular tissues (human cataractous and normal lenses) derived from ophthalmic patients or age-matched donors. The samples were used to test imidazole-containing peptidomimetic chemical/pharmacological chaperones in relation to oxidative stress induced by reaction with lipid peroxides or advanced non-enzymaticglycation processes. Chaperone function is characterized by interaction with other proteins, mediating their folding, transport, and interaction with other molecules, lipid peroxidation products, and membranes. Although these therapies remain on hold pending further investigation, it was presented growing evidence demonstrating the 
ability of N-acetylcarnosine (lubricant eye drops) or carcinine pharmacological chaperone therapy to act as novel treatments for age-related cataracts, age-related macular degeneration, and ocular complications of diabetes [121].

\section{Conclusions}

Oxidative stress is considered to be of importance in the management of the aging process. The free radical theory of aging assumes that the molecular basis of aging is derived from an accumulation of oxidative damage to cells during their lifetime as a result of excessive ROS produced as a result of aerobic metabolism. While the skin has extremely effective antioxidant activity during aging, ROS levels rise and antioxidant activities decline. The ROS requires multiple MAP kinase pathways in the induction of AP-1, in turn, regulates the expression of MMP providing a plausible mechanism for the increased degradation of collagen in aged human skin. In this process the mitochondria has an important role. And in the accumulation of mutations in mitochondrial DNA occur an imbalance in the expression of antioxidant enzymes results in greater overproduction of ROS. Apoptosis probably is hyper-regulated in the aging process and also is related to oxidative stress.

Other causes that can trigger the aging process are the shortening of telomere DNA and the cellular senescense because the cells do not suffer divisions. The diet is closely related to aging and the nutrition directly affects the skin. The aging can be related also with genetics and individual mutations in humans can cause premature aging syndromes and altered expression of single genes related to stess oxidative or apoptosis. The influence of the environment, called solar UV irradiation, is of considerable importance to skin aging and historically the photoaging and chronological skin aging is well studied. Finally the smoking and pollution are also closely related to aging process and can be considered as a theory.

Taken all together, these theories can act alone or in conjunction leading to skin aging.

Mechanism of shortening telomeres is not completely known about skin aging. The functions of specific miRNAs in cell cycle checkpoints, apoptosis, differentiation and other aspects of the cellular responses to UV irradiation require detailed studies.

About the future considerations in the field of skin aging, by means of study mechanisms that carry to understanding the skin aging to get new drugs that can help improve the treatment of aging skin and anti-wrinkles.

About the potential therapeutic to reverse skin aging, since the effectiveness of endogenous antioxidant system is diminished during aging, the exogenous supplementation of antioxidants might be a protective strategy against age-associated skin oxidative damage. Then, oxidative stress is a problem of skin cells and endogenous as well as exogenous antioxidants could play an important role in decreasing it [122].

\section{Acknowledgements}

To Sao Paulo Research Foundation (FAPESP), National Council of Technological and Scientific Development (CNPq).

\section{References}

[1] Prost-Squarcioni, C., Fraitag, S., Heller, M. and Boehm, N. (2008) Functional Histology of Dermis. Annales de Dermatologie et de Venereologie, 135, 15-20.

[2] Gragnani, A., Müller, B.R., Silva, I.D., Noronha, S.M. and Ferreira, L.M. (2013) Keratinocyte Growth Factor, Tumor Necrosis Factor-Alpha and Interleukin-1 Beta Gene Expression in Cultured Fibroblasts and Keratinocytes from Burned Patients. Acta Cirúrgica Brasileira, 28, 551-558. http://dx.doi.org/10.1590/S0102-86502013000800001

[3] Gragnani, A., Sobral, C.S. and Ferreira, L.M. (2007) Thermolysin in Human Cultured Keratinocyte Isolation. Brazilian Journal of Biology, 67, 105-109. http://dx.doi.org/10.1590/S1519-69842007000100014

[4] Sobral, C.S., Gragnani, A., Cao, X., Morgan, J.R. and Ferreira, L.M. (2007) Human Keratinocytes Cultured on Collagen Matrix Used as an Experimental Burn Model. Journal of Burns and Wounds, 7, e6.

[5] Porcheron, A., Mauger, E. and Russell, R. (2013) Aspects of Facial Contrast Decrease with Age and Are Cues for Age Perception. PLoS ONE, 8, Article ID: e57985. http://dx.doi.org/10.1371/journal.pone.0057985

[6] Puizina-Ivić, N. (2008) Skin Aging. Acta Dermatovenerologica Alpina, Panonica, et Adriatica, 17, 47-54.

[7] Du, C., Anderson, A., Lortie, M., Parsons, R. and Bodnar, A. (2013) Oxidative Damage and Cellular Defense Mechanisms in Sea Urchin Models of Aging. Free Radical Biology Medicine, 63, 254-263. http://dx.doi.org/10.1016/j.freeradbiomed.2013.05.023 
[8] Viña, J., Borras, C., Abdelaziz, K.M., Garcia-Valles, R. and Gomez-Cabrera, M.C. (2013) The Free Radical Theory of Aging Revisited: The Cell Signaling Disruption Theory of Aging. Antioxidants Redox Signaling, 19, 779-787. http://dx.doi.org/10.1089/ars.2012.5111

[9] Wei, Y., Zhang, Y.J., Cai, Y. and Xu, M.H. (2014) The Role of Mitochondria in mTOR-Regulated Longevity. Biological Reviews of the Cambridge Philosophical Society. http://dx.doi.org/10.1111/brv.12103

[10] Barja, G. (2013) Updating the Mitochondrial Free Radical Theory of Aging: An Integrated View, Key Aspects and Confounding Concepts. Antioxidants Redox Signaling, 19, 1420-1445. http://dx.doi.org/10.1089/ars.2012.5148

[11] Fisard, M. and Ravussin, E. (2006) Energy Metabolism and Oxidative Stress: Impact on the Metabolic Syndrome and the Aging Process. Endocrine, 29, 27-32. http://dx.doi.org/10.1385/ENDO:29:1:27

[12] Rattan, S.I. (2006) Theories of Biological Aging: Genes, Proteins and Free Radicals. Free Radical Research, 40, 12301238. http://dx.doi.org/10.1080/10715760600911303

[13] Ma, Y.S., Wu, S.B., Lee, W.Y., Cheng, J.S. and Wei, Y.H. (2009) Response to the Increase of Oxidative Stress and Mutation of Mitochondrial DNA in Aging. Biochimca et Biophysica Acta, 1790, 1021-1029.

[14] Gladyshev, V.N. (2014) The Free Radical Theory of Aging Is Dead. Long Live the Damage Theory! Antioxidants \& Redox Signaling, 20, 727-731.

[15] Kohl, E., Steinbauer, J., Landthaler, M. and Szeimies, R.M. (2011) Skin Ageing. Journal of the European Academy of Dermatology and Venereology, 25, 873-884. http://dx.doi.org/10.1111/j.1468-3083.2010.03963.x

[16] Ott, M., Gogvadze, V., Orrenius, S. and Zhivotovsky, B. (2007) Mitochondria, Oxidative Stress and Cell Death. Apoptosis, 12, 913-922. http://dx.doi.org/10.1007/s10495-007-0756-2

[17] Godic, A., Poljšak, B., Adamic, M. and Dahmane, R. (2014) The Role of Antioxidants in Skin Cancer Prevention and Treatment. Oxidative Medicine and Cellular Longevity, 2014, Article ID: 860479. http://dx.doi.org/10.1155/2014/860479

[18] Fraga, C.G., Motchnik, P.A., Shigenaga, M.K., Helbock, H.J., Jacob, R.A. and Ames, B.N. (1991) Ascorbic Acid Protects against Endogenous Oxidative DNA Damage in Human Sperm. Proceedings of the National Academy of Sciences of the United States of America, 88, 11003-11006. http://dx.doi.org/10.1073/pnas.88.24.11003

[19] Tanigawa, T., Kanazawa, S., Ichibori, R., Fujiwara, T., Magome, T., Shingaki, K., Miyata, S., Hata, Y., Tomita, K., Matsuda, K., Kubo, T., Tohyama, M., Yano, K. and Hosokawa, K. (2014) (+)-Catechin Protects Dermal Fibroblasts against Oxidative Stress-Induced Apoptosis. BMC Complementary \& Alternative Medicine, 14, 133. http://dx.doi.org/10.1186/1472-6882-14-133

[20] Randhawa, M., Sangar, V., Tucker-Samaras, S. and Southall, M. (2014) Metabolic Signature of Sun Exposed Skin Suggests Catabolic Pathway Overweighs Anabolic Pathway. PLoS ONE, 9, Article ID: e90367. http://dx.doi.org/10.1371/journal.pone.0090367

[21] Bennett, M.F., Robinson, M.K., Baron, E.D. and Cooper, K.D. (2008) Skin Immune Systems and Inflammation: Protector of the Skin or Promoter of Aging? Journal of Investigative Dermatology Symposium Proceedings, 13, 15-19. http://dx.doi.org/10.1038/jidsymp.2008.3

[22] Slominski, A., Tobin, D.J., Shibahara, S. and Wortsman, J. (2014) Melanin Pigmentation in Mammalian Skin and Its Hormonal Regulation. Physiological Reviews, 84, 1155-1228.

Menck, C.F.M. and Munford, V. (2014) DNA Repair Diseases: What Do They Tell Us about Cancer and Aging? Genetics and Molecular Biology, 37, 220-233.

[23] McKay, B.C., Becerril, C. and Ljungman, M. (2001) P53 Plays a Protective Role against UV- and Cisplatin-Induced Apoptosis in Transcription-Coupled Repair Proficient Fibroblasts. Oncogene, 20, 6805-6808. http://dx.doi.org/10.1038/sj.onc.1204901

[24] Andrade, L.N., Nathanson, J.L., Yeo, G.W., Menck, C.F. and Muotri, A.R. (2012) Evidence for Premature Aging Due to Oxidative Stress in iPSCs from Cockayne Syndrome. Human Molecular Genetics, 21, 3825-3834. http://dx.doi.org/10.1093/hmg/dds211

[25] Pascucci, B., Lemma, T., Iorio, E., Giovannini, S., Vaz, B., Iavarone, I., Calcagnile, A., Narciso, L., Degan, P., Podo, F., et al. (2012) An Altered Redox Balance Mediates the Hypersensitivity of Cockayne Syndrome Primary Fibroblasts to Oxidative Stress. Aging Cell, 11, 520-529. http://dx.doi.org/10.1111/j.1474-9726.2012.00815.X

[26] Brooks, P.J. (2012) Blinded by the UV Light: How the Focus on Transcription-Coupled NER Has Distracted from Understanding the Mechanisms of Cockayne Syndrome Neurologic Disease. DNA Repair, 12, 656-671. http://dx.doi.org/10.1016/j.dnarep.2013.04.018

[27] Batista, L.F., Roos, W.P., Kaina, B. and Menck, C.F. (2009) p53 Mutant Human Glioma Cells Are Sensitive to UVC-Induced Apoptosis Due to Impaired Cyclobutane Pyrimidine Dimer Removal. Molecular Cancer Research, 7, 237246. http://dx.doi.org/10.1158/1541-7786.MCR-08-0428

[28] Rastogi, R.P., Richa, K.A., Tyagi, M.B., et al. (2010) Molecular Mechanisms of Ultraviolet Radiation-Induced DNA 
Damage and Repair. Journal of Nucleic Acids, 2010, Article ID: 592980.

[29] Amano, S. (2009) Possible Involvement of Basement Membrane Damage in Skin Photo Aging. Journal of Investigative Dermatology Symposium Proceedings, 14, 2-7. http://dx.doi.org/10.1038/jidsymp.2009.5

[30] Tian, L.M., Xie, H.F., Xiao, X., Yang, T., Hu, Y.H., Wang, W.Z., Liu, L.S., Chen, X. and Li, J. (2011) Study on the Roles of $\beta$-Catenin in Hydrogen Peroxide-Induced Senescence in Human Skin Fibroblasts. Experimental Dermatology, 20, 836-838. http://dx.doi.org/10.1111/j.1600-0625.2011.01324.x

[31] Liu, J. and Lin, A. (2005) Role of JNK Activation in Apoptosis: A Double-Edged Sword. Cell Research, 15, 36-42. http://dx.doi.org/10.1038/sj.cr.7290262

[32] Volonte, D., Liu, Z., Musille, P.M., Stoppani, E., Wakabayashi, N., Di, Y.P., Lisanti, M.P., Kensler, T.W. and Galbiati, F. (2013) Inhibition of Nuclear Factor-Erythroid 2-Related Factor (Nrf2) by Caveolin-1 Promotes Stress-Induced Premature Senescence. Molecular Biology of the Cell, 24, 1852-1862. http://dx.doi.org/10.1091/mbc.E12-09-0666

[33] Sanz, A., Pamplona, R. and Barja, G. (2006) Is the Mitochondrial Free Radical Theory of Aging Intact? Antioxidants \& Redox Signaling, 8, 582-599. http://dx.doi.org/10.1089/ars.2006.8.582

[34] Lesenefsky, E. and Hoppel, C. (2006) Oxidative Phosphorylation and Aging. Ageing Research Reviews, 5, $402-433$. http://dx.doi.org/10.1016/j.arr.2006.04.001

[35] Wang, C.H., Wu, S.B., Wu, Y.T. and Wei, Y.H. (2013) Oxidative Stress Response Elicited by Mitochondrial Dysfunction: Implication in the Pathophysiology of Aging. Experimental Biology and Medicine, 238, 450-460. http://dx.doi.org/10.1177/1535370213493069

[36] Gregersen, N., Hansen, J. and Palmfeldt, J. (2012) Mitochondrial Proteomics-A Tool for the Study of Metabolic Disorders. Journal of Inherited Metabolic Disease, 35, 715-726. http://dx.doi.org/10.1007/s10545-012-9480-3

[37] Menon, G.K., Dal Farra, C., Botto, J.M. and Domloge, N. (2010) Mitochondria: A New Focus as an Anti-Aging Target in Skin Care. Journal of Cosmetic Dermatology, 9, 122-131. http://dx.doi.org/10.1111/j.1473-2165.2010.00496.X

[38] Avci, P., Sadasivam, M., Gupta, A., De Melo, W.C., Huang, Y.Y., Yin, R., Chandran, R., Kumar, R., Otufowora, A., Nyame, T. and Hamblin, M.R. (2013) Animal Models of Skin Disease for Drug Discovery. Expert Opinion on Drug Discovery, 8, 331-355. http://dx.doi.org/10.1517/17460441.2013.761202

[39] Chiba, Y., Yamashita, Y., Ueno, M., Fujisawa, H., Hirayoshi, K., Hohmura, K., Tomimoto, H., Akiguchi, I., Satoh, M., Shimada, A. and Hosokawa, M. (2005) Cultured Murine Dermal Fibroblast-Like Cells from Senescence-Accelerated Mice as in Vitro Models for Higher Oxidative Stress Due to Mitochondrial Alterations. The Journals of Gerontology Series A, 60, 1087-1098. http://dx.doi.org/10.1093/gerona/60.9.1087

[40] Orren, D.K. (2006) Werner Syndrome: Molecular Insights into the Relationships between Defective DNA Metabolism, Genomic Instability, Cancer and Aging. Frontiers in Bioscience, 11, 2657-2671. http://dx.doi.org/10.2741/1999

[41] Crabbe, L., Jauch, A., Naeger, C.M., Holtgreve-Grez, H. and Karlseder, J. (2007) Telomere Dysfunction as a Cause of Genomic Instability in Werner Syndrome. Proceedings of the National Academy of Sciences of the United States of America, 104, 2205-2210. http://dx.doi.org/10.1073/pnas.0609410104

[42] Kelland, L. (2007) Targeting the Limitless Replicative Potential of Cancer: The Telomerase/Telomere Pathway. Clinical Cancer Research, 13, 4960-4963. http://dx.doi.org/10.1158/1078-0432.CCR-07-0422

[43] Finkel, T., Serrano, M. and Blasco, M.A. (2007) The Common Biology of Cancer and Ageing. Nature, 448, 767-774. http://dx.doi.org/10.1038/nature05985

[44] Nakagawa, H. and Opitz, O.G. (2007) Inducing Cellular Senescence Using Defined Genetic Elements. Methods in Molecular Biology, 371, 167-178. http://dx.doi.org/10.1007/978-1-59745-361-5_13

[45] Olovnikov, A.M. (2007) Hypothesis: Lifespan Is Regulated by Chronomere DNA of the Hypothalamus. Journal of Alzheimer's Disease, 11, 241-252.

[46] Buckingham, E.M. and Klingelhutz, A.J. (2011) The Role of Telomeres in the Ageing of Human Skin. Experimental Dermatology, 20, 297-302. http://dx.doi.org/10.1111/j.1600-0625.2010.01242.x

[47] Burton, D.G. (2009) Cellular Senescence, Ageing and Disease. Age, 31, 1-9. http://dx.doi.org/10.1007/s11357-008-9075-y

[48] Burton, D.G.A., Allen, M.C., Bird, J.L.E. and Faragher, R.G.A. (2005) Bridging the Gap: Ageing, Pharmacokinetics and Pharmacodynamics. Journal of Pharmacy and Pharmacology, 57, 671-679. http://dx.doi.org/10.1211/0022357056163

[49] Burton, D.G.A., Sheerin, A., Ostler, E.L., Smith, K., Giles, P.J., Lowe, J., et al. (2007) Cyclin D1 Over-Expression Permits the Reproducible Detection of Senescent Human Vascular Smooth Muscle Cells. Annals of the New York Academy of Sciences, 1119, 20-31. http://dx.doi.org/10.1196/annals.1404.026

[50] Campisi, J. (1997) Aging and Cancer: The Double-Edged Sword of Replicative Senescence. Journal of the American Geriatrics Society, 45, 482-488 
[51] Campisi, J. (1997) The Biology of Replicative Senescence. European Journal of Cancer, 33, 703-709. http://dx.doi.org/10.1016/S0959-8049(96)00058-5

[52] Campisi J. (1998) The Role of Cellular Senescence in Skin Aging. Journal of Investigative Dermatology Symposium Proceedings, 3, 1-5. http://dx.doi.org/10.1038/jidsymp.1998.2

[53] Mancini, M., Lena, A.M., Saintigny, G., Mahé, C., Di Daniele, N., Melino, G. and Candi, E. (2014) MicroRNAs in Human Skin Ageing. Ageing Research Reviews.

[54] Lotfi, R.A., El Zawahry, K.M., Kamar, Z.A. and Hashem, Z. (2014) Effects of Smoking on Human Telomerase Reverse Transcriptase Expression in the Skin. International Journal of Dermatology.

[55] Yin, B. and Jiang, X. (2013) Telomere Shortening in Cultured Human Dermal Fibroblasts Is Associated with Acute Photodamage Induced by UVA Irradiation. Postępy Dermatologii i Alergologii, 30, 13-18. http://dx.doi.org/10.5114/pdia.2013.33374

[56] Herbig, U., Ferreira, M., Condel, L., Carey, D. and Sedivy, J.M. (2006) Cellular Senescence in Aging Primates. Science, 311, 1257. http://dx.doi.org/10.1126/science.1122446

[57] Coppe, J.P., Kauser, K., Campisi, J. and Beausejour, C.M. (2006) Secretion of Vascular Endothelial Growth Factor by Primary Human Fibroblasts at Senescence. The Journal of Biological Chemistry, 281, 29568-29574. http://dx.doi.org/10.1074/jbc.M603307200

[58] Kletsas, D., Pratsinis, H., Mariatos, G., Zacharatos, P. and Gorgoulis, V.G. (2004) The Proinflammatory Phenotype of Senescent Cells: The p53-Mediated ICAM-1 Expression. Annals of the New York Academy of Sciences, 1019, 330-332. http://dx.doi.org/10.1196/annals.1297.056

[59] Warner, H.R. (2007) Is Cell Death and Replacement a Factor in Aging? Mechanisms of Ageing and Development, 128, 13-16. http://dx.doi.org/10.1016/j.mad.2006.11.004

[60] Orrenius, S., Gogvadze, V. and Zhivotovsky, B. (2007) Mitochondrial Oxidative Stress: Implications for Cell Death. Annual Review of Pharmacology and Toxicology, 47, 143-183. http://dx.doi.org/10.1146/annurev.pharmtox.47.120505.105122

[61] Hasty, P. and Christy, B.A. (2013) p53 as an Intervention Target for Cancer and Aging. Pathobiology of Aging \& AgeRelated Disease, 3.

[62] Cho, J.H., Lee, J.H., Lee, E.J., Nam, D., Shim, B.S., Song, M.Y., Kim, S.S., Kim, S.H., Jung, S.H., Chung, W.S. and Ahn, K.S. (2013) 8 $\beta$-Hydroxy-3-Oxopimar-15-Ene Exerts Anti-Inflammatory Effects by Inhibiting ROS-Mediated Activation of the TRAF6-ASK1-p38 Signaling Pathway. Immunopharmacology and Immunotoxicology, 35, 549-557. http://dx.doi.org/10.3109/08923973.2013.820742

[63] Wada, T. and Penninger, J.M. (2004) Mitogen-Activated Protein Kinases in Apoptosis Regulation. Oncogene, 23, 2838-2849. http://dx.doi.org/10.1038/sj.onc.1207556

[64] Strozyk, E. and Kulms, D. (2013) The Role of AKT/mTOR Pathway in Stress Response to UV-Irradiation: Implication in Skin Carcinogenesis by Regulation of Apoptosis, Autophagy and Senescence. International Journal of Molecular Sciences, 14, 15260-15285. http://dx.doi.org/10.3390/ijms140815260

[65] Schagen, S.K., Zampeli, V.A., Makrantonaki, E. and Zouboulis, C.C. (2012) Discovering the Link between Nutrition and Skin Aging. Dermato-Endocrinology, 4, 298-307. http://dx.doi.org/10.4161/derm.22876

[66] Draelos, Z.D. (2013) Aging Skin: The Role of Diet: Facts and Controversies. Clinics in Dermatology, 31, $701-706$. http://dx.doi.org/10.1016/j.clindermatol.2013.05.005

[67] Pluijm, S.M., Visser, M., Puts, M.T., Dik, M.G., Schalk, B.W., et al. (2007) Unhealthy Lifestyles during the Life Course: Association with Physical Decline in Late Life. JAMA, 297, 986-994.

[68] Testa, G., Biasi, F., Poli, G. and Chiarpotto, E. (2014) Calorie Restriction and Dietary Restriction Mimetics: A Strategy for Improving Healthy Aging and Longevity. Current Pharmaceutical Design, 20, 2950-2977. http://dx.doi.org/10.2174/13816128113196660699

[69] Jeyapalan, J.C., Ferreira, M., Sedivy, J.M. and Herbig, U. (2007) Accumulation of Senescent Cells in Mitotic Tissue of Aging Primates. Mechanisms of Ageing and Development, 128, 36-44. http://dx.doi.org/10.1016/j.mad.2006.11.008

[70] Freund, A., et al. (2010) Inflammatory Networks during Cellular Senescence: Causes and Consequences. Trends in Molecular Medicine, 16, 238-246. http://dx.doi.org/10.1016/j.molmed.2010.03.003

[71] Passos, J.F., et al. (2010) Feedback between p21 and Reactive Oxygen Production Is Necessary for Cell Senescence. Molecular Systems Biology, 6, 347. http://dx.doi.org/10.1038/msb.2010.5

[72] Xue, W., et al. (2007) Senescence and Tumour Clearance Is Triggered by p53 Restoration in Murine Liver Carcinomas. Nature, 445, 656-660. http://dx.doi.org/10.1038/nature05529

[73] Krtolica, A. and Campisi, J. (2002) Cancer and Aging: A Model for the Cancer Promoting Effects of the Aging Stroma. 
The International Journal of Biochemistry \& Cell Biology, 34, 1401-1414. http://dx.doi.org/10.1016/S1357-2725(02)00053-5

[74] Parrinello, S., et al. (2005) Stromal-Epithelial Interactions in Aging and Cancer: Senescent Fibroblasts Alter Epithelial Cell Differentiation. Journal of Cell Science, 118, 485-496. http://dx.doi.org/10.1242/jcs.01635

[75] Baker, D.J., et al. (2008) Opposing Roles for p16 ${ }^{\mathrm{Ink} 4 \mathrm{a}}$ and $\mathrm{p} 19^{\text {Arf }}$ in Senescence and Ageing Caused by BubR1 Insufficiency. Nature Cell Biology, 10, 825-836. http://dx.doi.org/10.1038/ncb1744

[76] Berryman, D.E., et al. (2008) Role of the GH/IGF-1 Axis in Lifespan and Healthspan: Lessons from Animal Models. Growth Hormone \& IGF Research, 18, 455-471. http://dx.doi.org/10.1016/j.ghir.2008.05.005

[77] Masoro, E.J. (2006) Dietary Restriction-Induced Life Extension: A Broadly Based Biological Phenomenon. Biogerontology, 7, 153-155. http://dx.doi.org/10.1007/s10522-006-9015-0

[78] Higami, Y., et al. (2006) Energy Restriction Lowers the Expression of Genes Linked to Inflammation, the Cytoskeleton, the Extracellular Matrix and Angiogenesis in Mouse Adipose Tissue. Journal of Nutrition, 136, 343-352.

[79] Wang, C., et al. (2010) Adult-Onset, Short-Term Dietary Restriction Reduces Cell Senescence in Mice. Aging, 2, 555566.

[80] Ezure, T. and Amano, S. (2010) Increased Subcutaneous Adipose Tissue Impairs Dermal Function in Diet-Induced Obese Mice. Experimental Dermatology, 19, 878-882. http://dx.doi.org/10.1111/j.1600-0625.2009.00970.x

[81] Hiebert, P.R., Boivin, W.A., Abraham, T., Pazooki, S., Zhao, H., Granville, D.J. and Granzyme, B. (2011) Contributes to Extracellular Matrix Remodeling and Skin Aging in Apolipoprotein E Knockout Mice. Experimental Gerontology, 46, 489-499. http://dx.doi.org/10.1016/j.exger.2011.02.004

[82] Ohnishi, M. and Razzaque, M.S. (2010) Dietary and Genetic Evidence for Phosphate Toxicity Accelerating Mammalian Aging. The FASEB Journal, 24, 3562-3571. http://dx.doi.org/10.1096/fj.09-152488

[83] Nagase, T., Akase, T., Sanada, H., Minematsu, T., Ibuki, A., Huang, L., Asada, M., Yoshimura, K., Nagase, M., Shimada, T., Aburada, M., Nakagami, G. and Sugama, J. (2013) Aging-Like Skin Changes in Metabolic Syndrome Model Mice Are Mediated by Mineralocorticoid Receptor Signaling. Aging Cell, 12, 50-57. http://dx.doi.org/10.1111/acel.12017

[84] Browner, W.S., Kahn, A.J., Ziv, E., Reiner, A.P., Oshima, J., et al. (2004) The Genetics of Human Longevity. American Journal of Medicine, 117, 851-860. http://dx.doi.org/10.1016/j.amjmed.2004.06.033

[85] Kirkwood, T. (2006) Ageing: Too Fast by Mistake. Nature, 444, 1015-1107. http://dx.doi.org/10.1038/4441015a

[86] Waaijer, M.E., Gunn, D.A., Catt, S.D., van Ginkel, M., de Craen, A.J., Hudson, N.M., van Heemst, D., Slagboom, P.E., Westendorp, R.G. and Maier, A.B. (2012) Morphometric Skin Characteristics Dependent on Chronological and Biological Age: The Leiden Longevity Study. Age, 34, 1543-1552. http://dx.doi.org/10.1007/s11357-011-9314-5

[87] Fisher, G.J. (2005) The Pathophysiology of Photoaging of The Skin. Cutis, 75, 5-9.

[88] Rattan, S.I. and Ali, R.E. (2007) Hormetic Prevention of Molecular Damage during Cellular Aging of Humanskin Fibroblasts and Keratinocytes. Annals of the New York Academy of Sciences, 1100, 424-430. http://dx.doi.org/10.1196/annals.1395.047

[89] Yaar, M. and Gilchrest, B.A. (2007) Photoageing: Mechanism, Prevention and Therapy. British Journal of Dermatology, 157, 874-887. http://dx.doi.org/10.1111/j.1365-2133.2007.08108.x

[90] Kosmadaki, M.G. and Gilchrest, B.A. (2004) The Role of Telomeres in Skin Aging/Photoaging. Micron, 35, $155-159$. http://dx.doi.org/10.1016/j.micron.2003.11.002

[91] Baumann, L. (2007) Skin Ageing and Its Treatment. The Journal of Pathology, 211, 241-251. http://dx.doi.org/10.1002/path.2098

[92] Sugimoto, M., Yamashita, R. and Ueda, M. (2006) Telomere Length of the Skin in Association with Chronological Aging and Photoaging. Journal of Dermatological Science, 43, 43-47. http://dx.doi.org/10.1016/j.jdermsci.2006.02.004

[93] Śpiewak, R. (2012) The Substantial Differences between Photoallergic and Phototoxic Reactions. Annals of Agricultural and Environmental Medicine, 19, 888-889.

[94] Landau, M. (2007) Exogenous Factors in Skin Aging. Current Problems in Dermatology, 35, 1-13.

[95] Federman, D.G. and Kravetz, J.D. (2007) Peripheral Arterial Disease: Diagnosis, Treatment and Systemic Implications. Clinics in Dermatology, 25, 93-100. http://dx.doi.org/10.1016/j.clindermatol.2006.09.006

[96] Morita, A., Torii, K., Maeda, A. and Yamaguchi, Y. (2009) Molecular Basis of Tobacco Smoke-Induced Premature Skin Aging. Journal of Investigative Dermatology Symposium Proceedings, 14, 53-55. http://dx.doi.org/10.1038/jidsymp.2009.13

[97] Ono, Y., Torii, K., Fritsche, E., Shintani, Y., Nishida, E., Nakamura, M., Shirakata, Y., Haarmann-Stemmann, T., Abel, 
J., Krutmann, J. and Morita, A. (2013) Role of the Aryl Hydrocarbon Receptor in Tobacco Smoke Extract-Induced Matrix Metalloproteinase-1 Expression. Experimental Dermatology, 22, 349-353. http://dx.doi.org/10.1111/exd.12148

[98] Garbe, C. and Eigentler, T.K. (2007) Diagnosis and Treatment of Cutaneous Melanoma: State of the Art 2006. Melanoma Research, 17, 117-127. http://dx.doi.org/10.1097/CMR.0b013e328042bb36

[99] Norval, M., Cullen, A.P., de Gruijl, F.R., Longstreth, J., Takizawa, Y., et al. (2007) The Effects on Human Health from Stratospheric Ozone Depletion and Its Interactions with Climate Change. Photochemical Photobiological Sciences, 6, 232-251. http://dx.doi.org/10.1039/b700018a

[100] Arnold, S.F. and Price, P.S. (2007) Modeling Mixtures Resulting from Concurrent Exposures to Multiple Sources. Toxicology and Applied Pharmacology, 223, 121-124. http://dx.doi.org/10.1016/j.taap.2006.11.032

[101] Valacchi, G., Sticozzi, C., Pecorelli, A., Cervellati, F., Cervellati, C. and Maioli, E. (2012) Cutaneous Responses to Environmental Stressors. Annals of the New York Academy of Sciences, 1271, 75-81. http://dx.doi.org/10.1111/j.1749-6632.2012.06724.x

[102] Vierkötter, A. (2011) Environmental Pollution and Skin Aging. Der Hautarzt, 62, 577-581. http://dx.doi.org/10.1007/s00105-011-2135-8

[103] Sarchio, S.N., Kok, L.F., O’Sullivan, C., Halliday, G.M., Byrne, S.N. (2012) Dermal Mast Cells Affect the Development of Sunlight-Induced Skin Tumours. Experimental Dermatology, 21, 241-248. http://dx.doi.org/10.1111/j.1600-0625.2012.01438.x

[104] Nagai, H., Noguchi, T., Takeda, K. and Ichijo, H. (2007) Pathophysiological Roles of ASK1-MAP Kinase Signaling Pathways. Journal of Biochemistry and Molecular Biology, 40, 1-6. http://dx.doi.org/10.5483/BMBRep.2007.40.1.001

[105] Cornwell, D.G. and Ma, J. (2007) Studies in Vitamin E: Biochemistry and Molecular Biology of Tocopherol Quinones. Vitamins Hormones, 76, 99-134. http://dx.doi.org/10.1016/S0083-6729(07)76005-3

[106] Azzi, A., Gysin, R., Kempna, P., Munteanu, A., Negis, Y., et al. (2004) Vitamin E Mediates Cell Signaling and Regulation of Gene Expression. Annals of the New York Academy of Sciences, 1031, 86-95. http://dx.doi.org/10.1196/annals.1331.009

[107] Liu, M., Xu, Y., Han, X., Liang, C., Yin, L., Xu, L., Qi, Y., Zhao, Y., Peng, J. and Sun, C. (2014) Potent Effects of Flavonoid-Rich Extract from Rosa laevigata Michx Fruit against Hydrogen Peroxide-Induced Damage in PC12 Cells via Attenuation of Oxidative Stress, Inflammation and Apoptosis. Molecules, 19, 11816-11832. http://dx.doi.org/10.3390/molecules190811816

[108] Tulah, A.S. and Birch-Machin, M.A. (2013) Stressed out Mitochondria: The Role of Mitochondria in Ageing and Cancer Focussing on Strategies and Opportunities in Human Skin. Mitochondrion, 13, 444-453. http://dx.doi.org/10.1016/j.mito.2012.11.007

[109] OyetakinWhite, P., Tribout, H. and Baron, E. (2012) Protective Mechanisms of Green Tea Polyphenols in Skin. Oxidative Medicine and Cellular Longevity, 2012, Article ID: 560682.

[110] Korkina, L.G., Pastore, S., Dellambra, E. and De Luca, C. (2013) New Molecular and Cellular Targets for Chemoprevention and Treatment of Skin Tumors by Plant Polyphenols: A Critical Review. Current Medicinal Chemistry, 20, 852-868.

[111] Zouboulis, C.C. and Makrantonaki, E. (2011) Clinical Aspects and Molecular Diagnostics of Skin Aging. Clinics in Dermatology, 29, 3-14. http://dx.doi.org/10.1016/j.clindermatol.2010.07.001

[112] Kuphal, S. and Bosserhoff, A. (2009) Recent Progress in Understanding the Pathology of Malignant Melanoma. The Journal of Pathology, 219, 400-409. http://dx.doi.org/10.1002/path.2617

[113] Kasper, M., Jaks, V., Hohl, D. and Toftgård, R. (2012) Basal Cell Carcinoma-Molecular Biology and Potential New Therapies. Journal of Clinical Investigation, 122, 455-463. http://dx.doi.org/10.1172/JCI58779

[114] Mimeault, M. and Batra, S.K. (2010) Recent Advances on Skin-Resident Stem/Progenitor Cell Functions in Skinregeneration, Aging and Cancers and Novel Anti-Aging and Cancer Therapies. Journal of Cellular and Molecular Medicine, 14, 116-134. http://dx.doi.org/10.1111/j.1582-4934.2009.00885.x

[115] Jackson, R.L., Greiwe, J.S. and Schwen, R.J. (2011) Ageing Skin: Oestrogen Receptor $\beta$ Agonists Offer an Approach to Change the Outcome. Experimental Dermatology, 20, 879-882. http://dx.doi.org/10.1111/j.1600-0625.2011.01362.x

[116] Emmerson, E. and Hardman, M.J. (2012) The Role of Estrogen Deficiency in Skin Ageing and Wound Healing. Biogerontology, 13, 3-20. http://dx.doi.org/10.1007/s10522-011-9322-y

[117] Thornton, M.J. (2013) Estrogens and Aging Skin. Dermato-Endocrinology, 5, 264-270. http://dx.doi.org/10.4161/derm.23872

[118] Pageon, H. (2010) Reaction of Glycation and Human Skin: The Effects on the Skin and Its Components, Reconstructed Skin as a Model. Pathologie Biologie, 58, 226-231. http://dx.doi.org/10.1016/j.patbio.2009.09.009

[119] Salbach, J., Rachner, T.D., Rauner, M., Hempel, U., Anderegg, U., Franz, S., Simon, J.C. and Hofbauer, L.C. (2012) 
Regenerative Potential of Glycosaminoglycans for Skin and Bone. Journal of Molecular Medicine, 90, 625-635. http://dx.doi.org/10.1007/s00109-011-0843-2

[120] Farris, P.K. (2011) Innovative Cosmeceuticals: Sirtuin Activators and Anti-Glycationcompounds. Seminars in Cutaneous Medicine and Surgery, 30, 163-166. http://dx.doi.org/10.1016/j.sder.2011.05.004

[121] Babizhayev, M.A. and Yegorov, Y.E. (2010) Therapeutic Uses of Drug-Carrier Systems for Imidazole-Containing Dipeptide Compounds That Act as Pharmacological Chaperones and Have Significant Impact on the Treatment of Chronic Diseases Associated with Increased Oxidative Stress and the Formation of Advanced Glycation End Products. Critical Reviews in Therapeutic Drug Carrier Systems, 27, 85-154. http://dx.doi.org/10.1615/CritRevTherDrugCarrierSyst.v27.i2.10

[122] Poljsak, B., Dahmane, R. and Godic, A. (2013) Skin and Antioxidants. Journal of Cosmetic and Laser Therapy, 15, 107-113. http://dx.doi.org/10.3109/14764172.2012.758380 
Scientific Research Publishing (SCIRP) is one of the largest Open Access journal publishers. It is currently publishing more than 200 open access, online, peer-reviewed journals covering a wide range of academic disciplines. SCIRP serves the worldwide academic communities and contributes to the progress and application of science with its publication.

Other selected journals from SCIRP are listed as below. Submit your manuscript to us via either submit@scirp.org or Online Submission Portal.
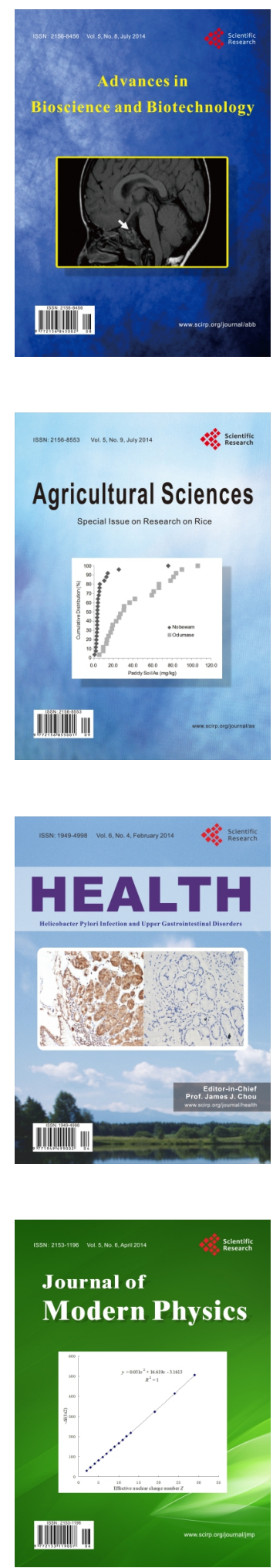
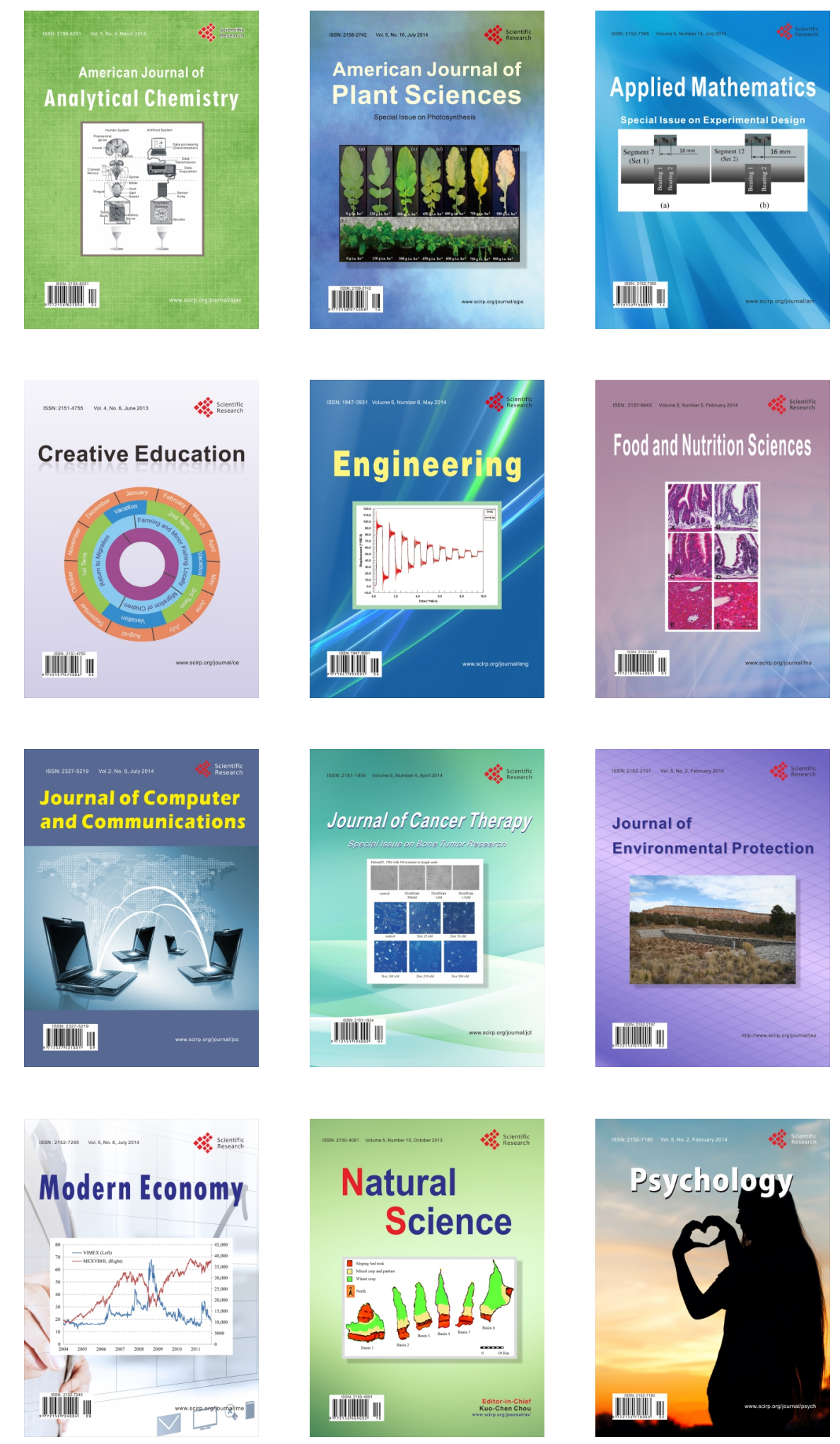